\title{
Research on the "flipped classroom" teaching mode based on the idea of innovation and entrepreneurship education
}

\author{
Zhao Hong ${ }^{1}$ \\ Liaoning Institute of Science and Technology, Benxi City, Liaoning Province117000, China
}

Keywords: innovative education; flipped classroom; teaching mode

\begin{abstract}
Information technology is a brilliant achievement of human civilization in the 21 st century. With the development of information technology, our work and life become more simple and efficient, its simple and efficient superiority covers all areas of society. As an important part of society, education is deeply influenced by information technology. It provides a new educational model for college classroom teaching, especially for application - oriented universities of science and engineering, which has structural innovative significance. This paper will explore the " flipped classroom" teaching model of innovative education.
\end{abstract}

\section{Introduction}

The " flipped classroom" subverts the original educational concept, it is a creative teaching mode and it is the inevitable product of the development of the times, but also the external reflection of the maturity of education. The "flipped classroom" is a student-centered teaching mode, the teacher records the classroom teaching process in the form of a micro-lesson by means of multimedia technology, information technology, video, audio processing technology, etc., and upload it to the network for students to receive, require students to learn video teaching content outside the classroom teaching independently. In classroom teaching, knowledge transmission within the scope of textbooks is no longer the focus of teaching, solving all kinds of problems encountered by students in autonomous learning is the focus of classroom teaching. Thus, the " flipped classroom" is essentially an innovative teaching mode, and with the further development of information technology and the deepening of quality education, it could become the dominant teaching mode in the future, for application - oriented universities of science and engineering, it can not only train students' practical operation ability, but also cultivate students' scientific thinking mode, stimulate innovative consciousness and effectively realize classroom teaching objectives.

\section{The differences between traditional classroom teaching and " flipped classroom"}

In order to fully understand the innovative concept of " flipped classroom", we must introduce the traditional classroom teaching as a reference factor, and compare the two.

\subsection{Traditional classroom teaching}

According to the traditional teaching thought, knowledge is transmitted to students through teachers' teaching, so students' learning process is the process of passive acceptance of knowledge. ${ }^{[1}$ Use the diagram to express the traditional classroom teaching mode as follows: 


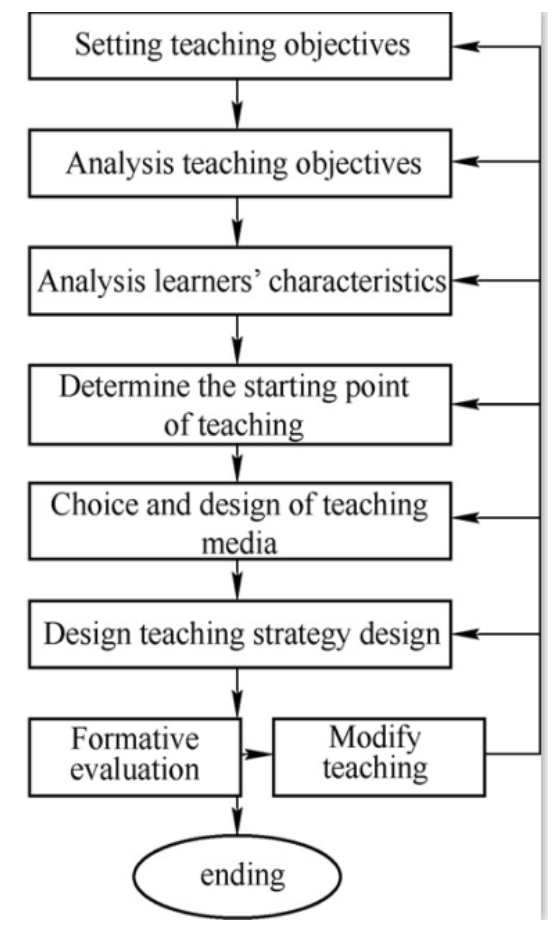

Figure 1 the traditional classroom teaching mode

From the diagram, we can see that the logic of traditional classroom teaching is more rigorous, emphasizing the order of teaching and completing the teaching contents according to the steps.But there are three obvious shortcomings: First, college teachers occupy the initiative completely in the classroom teaching, master the content, rhythm, methods of the classroom teaching, and students are always in a passive position; Second, college teachers in classroom teaching is basically in accordance with the preparation plan lessons step by step, that did not realize the interaction between teachers and students in the whole classroom teaching, teachers cannot collect feedback from students timely, and not possible to understand the students' knowledge in the first place; Third, the traditional classroom teaching presents a linear connection mode completely, its overall teaching structure presents a closed one-way transmission mode, and it does not make the content and steps of classroom teaching to achieve mutual connection, divergent extension.

\section{2 " flipped classroom" teaching}

The innovation of the " flipped classroom" lies in the " flip", " flip" is to change the position of teachers and students in the classroom teaching. In the " flipped classroom", students become the main body of classroom teaching, all teachers' teaching should take students as the starting point. Therefore it makes a structural setting that subvert the traditional cognition in the teaching mode: 


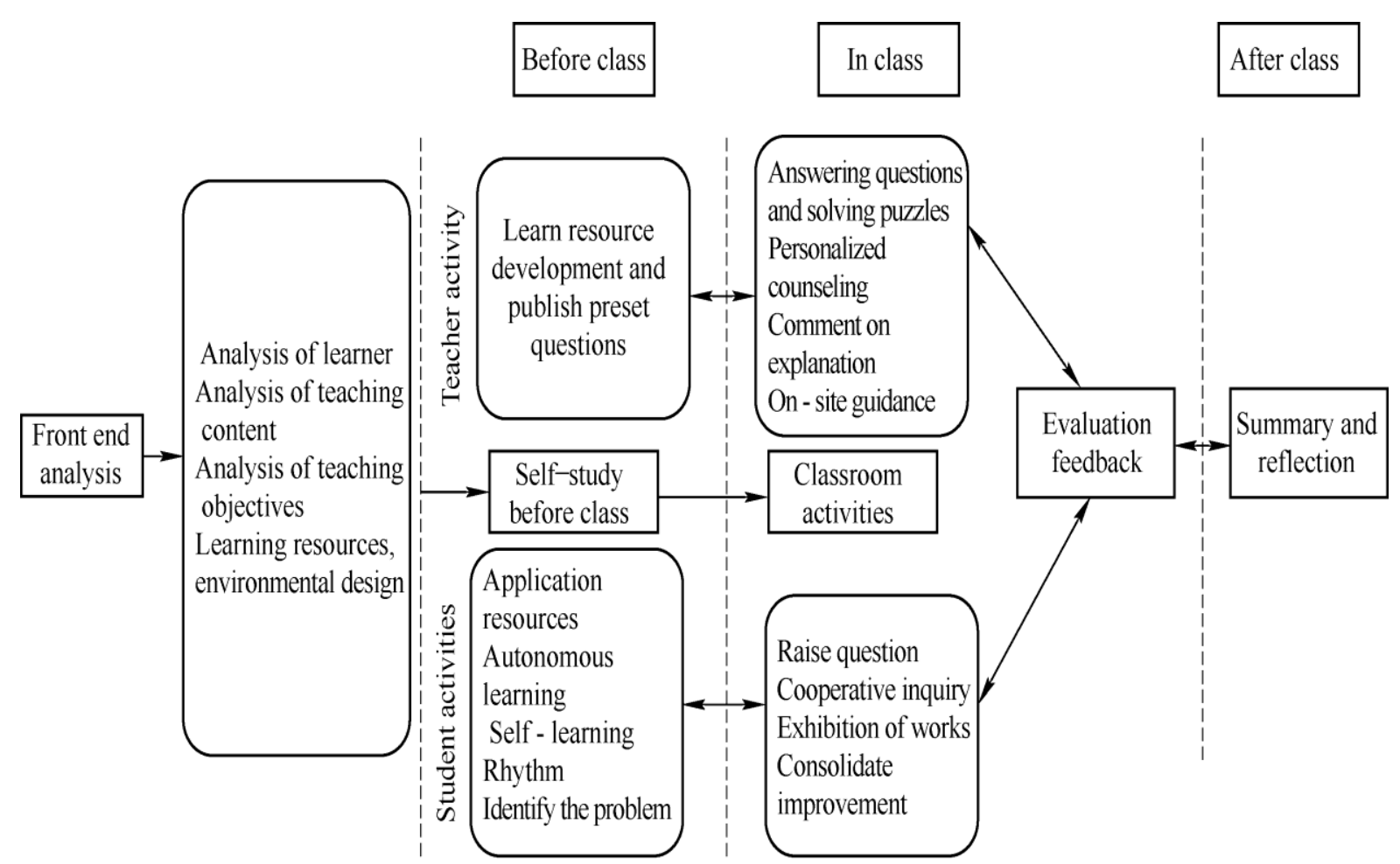

Figure 2 the " flipped classroom" structure diagram

From the " flipped classroom" structure diagram, we can find that it consists of four parts, including front end analysis, before class, in class and after class analysis. The front end analysis is before the classroom teaching, teachers need to start from a global perspective to consider each element involved in classroom teaching, analysis and judgment of different elements respectively, and then develop detailed and feasible creative teaching mode around these elements. The pre-class and in-class of " flipped classroom" most directly reflect the creativity, in the pre-class part, the teacher uploads the recorded classroom teaching content to the network by means of information technology, then students can choose learning time and learning methods flexibly to learn through the internet. In college, the " flipped classroom" pre-class video content usually requires students to complete the project homework, students need to complete the homework after learning knowledge content to consolidate the knowledge learned. The " flipped classroom" in-class course focuses on solving the difficulties and problems encountered by students in learning, the form of classroom teaching is " answering questions and solving puzzles". Finally is after-school reflection, this is a key step in all teaching modes, found the problem in the reflection, continuously improve the college teachers' classroom teaching level in the process of solving the problem.

\section{Analysis on the feasibility of the " flipped classroom" in application - oriented undergraduate universities}

In order to further study the " flipped classroom" and determine the feasibility of " flipped classroom" in the application - oriented undergraduate universities, the author combines the teaching content of "flipped classroom" and adopts the questionnaire survey to analyze the students in the university. The questionnaire mainly revolve around hardware and software required for the " flipped classroom", including students' satisfaction with the school's multimedia technology, whether the school set up a special micro-lesson recording classroom, whether satisfied with the video and audio content of the later period, whether satisfied with the teacher's education and teaching level, whether satisfied with the teacher's " flipped classroom" teaching mode, whether they will learn independently, etc.. The process and results of the survey are shown in tabular form, as shown below: 
(1) The gender distribution of subjects

\begin{tabular}{|l|l|l|}
\hline Gender & male & female \\
\hline Number & 211 & 279 \\
\hline Percentage & $43.1 \%$ & $56.9 \%$ \\
\hline
\end{tabular}

(2) The grade distribution of subjects

\begin{tabular}{|c|c|c|c|c|}
\hline Grade & Grade one & grade two & grade three & grade four \\
\hline Number & 83 & 164 & 113 & 130 \\
\hline Percentage & $17 \%$ & $33 \%$ & $23 \%$ & $27 \%$ \\
\hline
\end{tabular}

(3) The recognition of autonomous learning

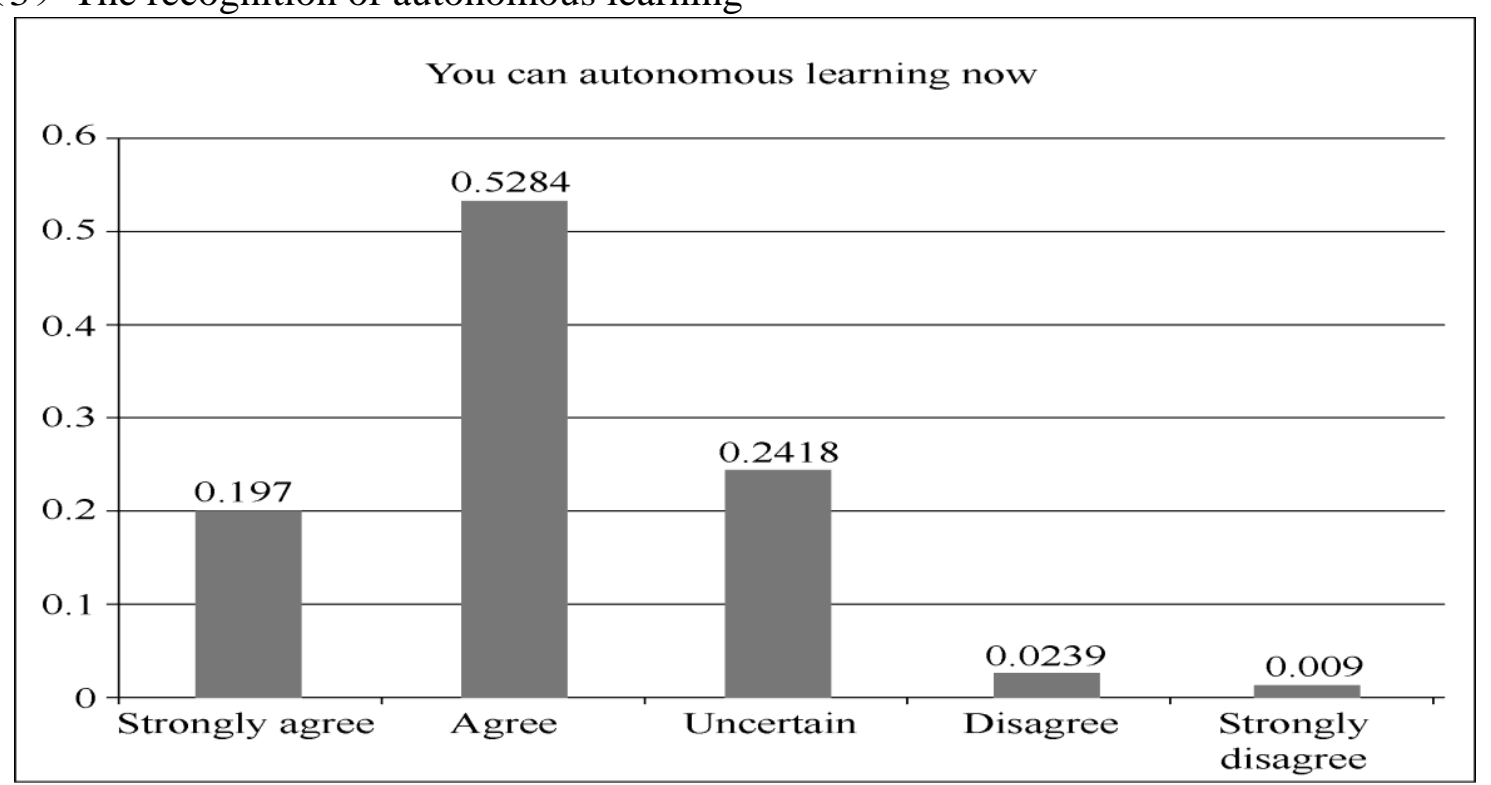

Figure 3 . "The recognition of autonomous learning" survey result

(4) Weather you can understand the statement of the problem

You can understand the description of the problem

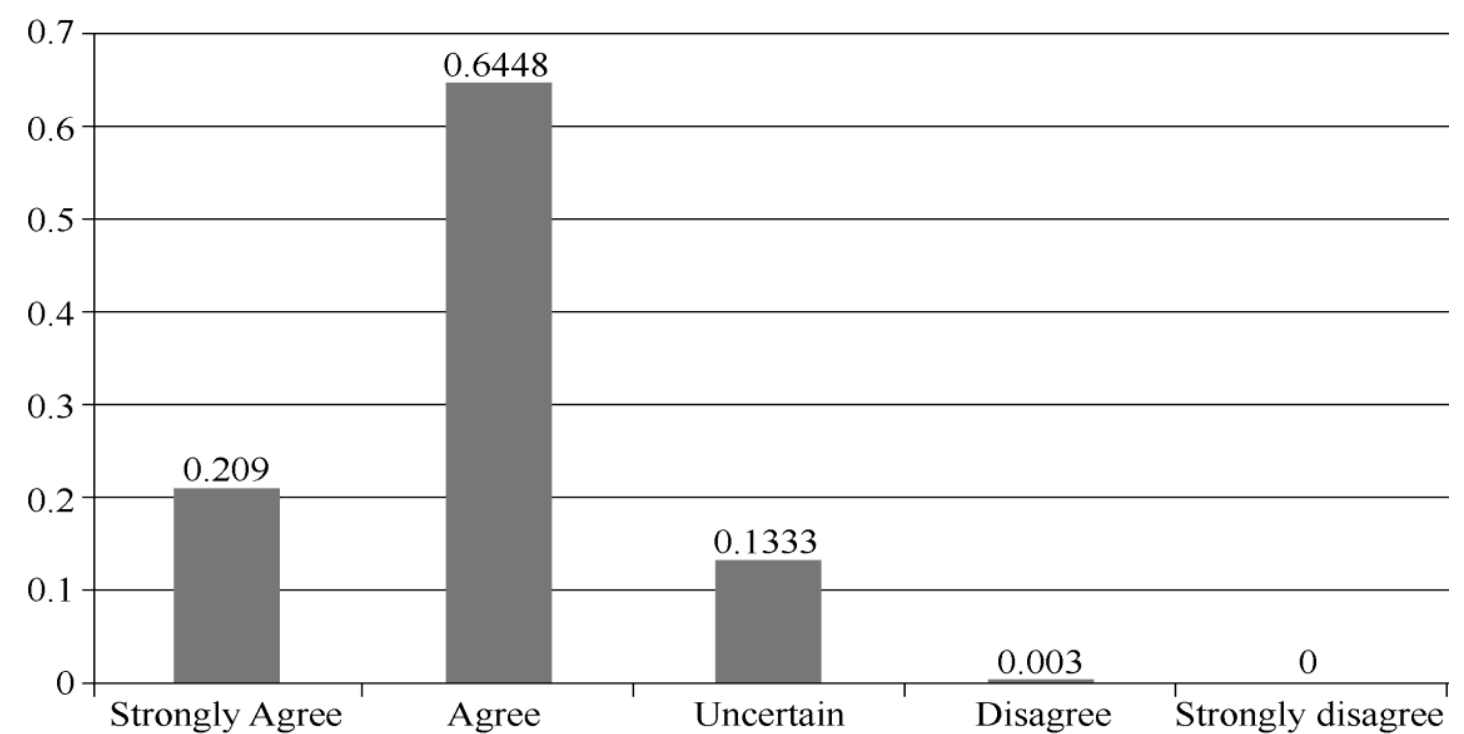

Figure 4. "Weather you can understand the statement of the problem" survey result 
(5) Whether you can find multiple solutions to a problem

You can often find multiple solutions to a problem

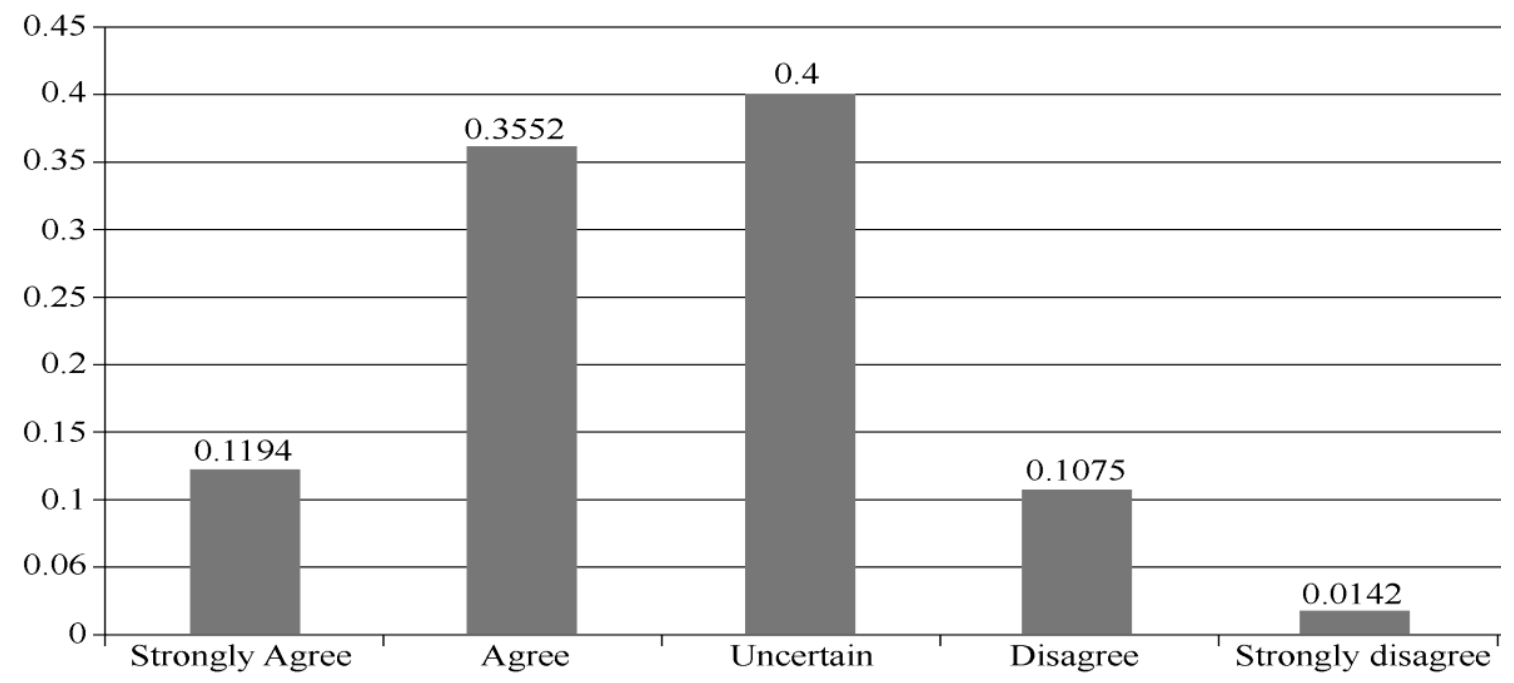

Figure 5. "whether you can find multiple solutions to a problem" survey result

(6) Whether you will be interested in things and actively explore

You are curious about many things and try to explore innovation

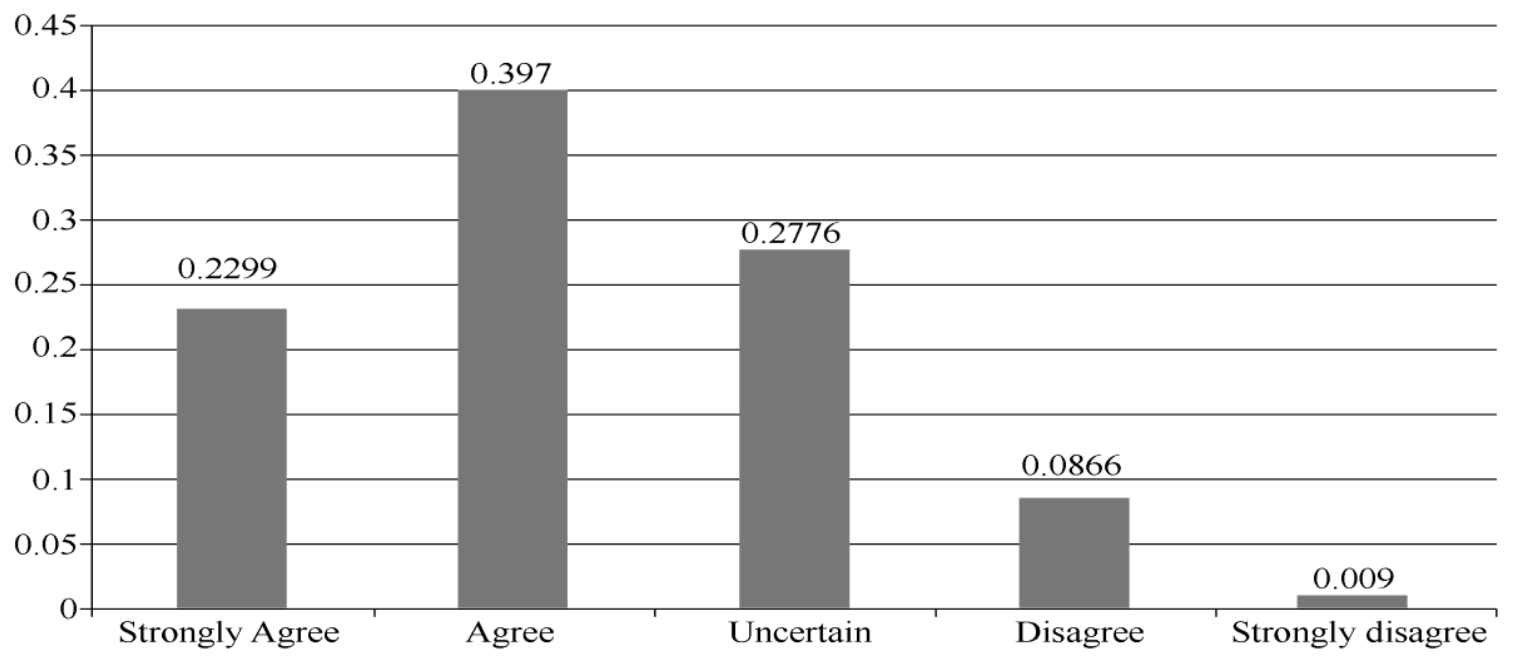

Figure 6. "Whether you will be interested in things and actively explore" survey result

The above six survey charts show the attitude of college students toward " flipped classroom", the choice of factors by strongly agree, agree, uncertain, disagree and strongly disagree, from the data we can see that the the amount of support for "agree" is significantly higher than others, so it is feasible to carry out "flipped classroom" in colleges and universities. Students not only believe that colleges and universities basically have hardware technology to carry out the " flipped classroom", but also think that college teachers can be fully qualified for the "flipped classroom" teaching tasks. Therefore, as long as colleges and universities seriously study the teaching strategy of " flipped classroom" and provide high-quality hardware support, the " flipped classroom" can achieve good teaching results in colleges and universities.

\section{The teaching strategy of " flipped classroom" based on innovative education}

The teaching mode of " flipped classroom" originated from the Woodland Park High School in the spring of 2007. The "flipped classroom" design idea was introduced into China in early 2012. [2] Thus, compared with the developed countries in Europe and the United States, there is still a certain 
gap in the teaching research of " flipped classroom" in China, so far, the " flipped classroom" has gone through only six years. The talent training goal of the application - oriented universities is to train the technical professionals needed by the society, it is necessary to innovate education and actively study the teaching strategy of " flipped classroom",in order to cultivate talents in application - oriented universities to meet the needs of the society. The following is to take entrepreneurial management as an example, illustrate the " flipped classroom" teaching strategy:

\subsection{School creates information network sharing platform}

The "flipped classroom" requires the support of network technology platform, due to the objective conditions of a large number of students in colleges, the requirements of network technology platform are higher. Therefore, colleges and universities should create an information network platform that can serve the whole school teachers and students, and configure professional computer technicians to maintain and operate the network sharing platform, so that teachers and students can download and learn at any time.

\subsection{Improving teaching efficiency by means of micro - lesson teaching}

Micro - lesson teaching is an important part of the " flipped classroom", it can make a thorough and detailed analysis of the key and difficult points of teaching, and deepen students' understanding of knowledge. In entrepreneurship management teaching, teachers should consider the content of micro-lesson from two dimensions, in order to improve teaching efficiency. The first comes from the characteristics of the micro-lesson itself, the micro-lesson time is short, usually less than 10 minutes, This requires the college teachers to be highly condensed in their knowledge, to achieve the effect of concise, on this basis, then extract a point, this point can be difficult or important , around the refined point to explain in detail; The second comes from the entrepreneurship management course teaching, before carrying out the course teaching, we should fully understand the students in depth, know what the students are interested in, and take the interest of the students as the starting point to carry out classroom teaching. Entrepreneurship management needs to be supported by an entity, it can be based on a start-up company in the market economy, take the company as a sample to carry out micro-lesson teaching. Such as " logical thinking" , it is a start-up company based on knowledge services, the current payment of the masses has reached more than one million, the profit projects of " logical thinking" including a daily listening books, economics, law, literature and other columns, of course, it also covers the book mall. Luo Zhenyu's annual cross-year speech at Shenzhen satellite TV is even more wonderful, so that many audiences through cross-year speech to realize the brand of " logical thinking", know what this app can bring to them.

Combined with this case, the teaching content of entrepreneurship management can be covered in the micro-lesson, although the content to be told is rich and colorful, and even find it impossible to speak. In the micro-lesson, there must be a focus in micro-lesson, which is to carry out in-depth explanation around a key content. Such as " logical thinking", it is difficult to analyze from the perspective of entrepreneurship management in the limited time of micro-lesson, we only need to carry out in-depth analysis of the brand influence promotion strategy which can achieve good teaching effect. In homework assignments, teachers can ask students to download app, using the theory of entrepreneurial knowledge acquired by the team to analyze the APP, finally let the discussion and research results in the form of group papers presented to teachers.

\subsection{The classroom teaching is people-oriented, in the way of interaction between teachers and students " answering questions and solving puzzles"}

In the classroom teaching link of " flipped classroom", students should be taken as the center, the content of the teaching material is no longer the focus of classroom teaching, the real point is the various problems that students meet in the process of autonomous learning,, teachers should explain the problems one by one, as far as possible to let students solve all kinds of confusion in the limited time of classroom teaching. 


\section{Conclusion}

The Ministry of education issued the " education information ten years development plan ( 2011 2020 )" has clearly pointed out that: "Higher education informatization is an effective way to promote the reform and innovation of higher education and improve the quality of higher education, and it is the innovation frontier of the development of education informatization." [3]Further strengthen the infrastructure and information resources construction, focus on promoting the in-depth integration of information technology and higher education, and promote the modernization of educational contents and teaching methods, training of innovative personnel, scientific research organizations and social service mode, and promote the innovation of cultural heritage and promote the overall improvement of the quality of higher education. ${ }^{[3]}$ Under the great attention of the party and the state, information technology has become an important teaching form in application - oriented universities. Therefore, college teachers should actively study the " flipped classroom" teaching mode, stimulate students' interest in learning, and comprehensively improve students' professional knowledge and skills.

\section{Acknowledgement}

This paper is about the project " research on the role of mass technological innovation activities in shaping enterprise innovation culture" ( LNKX2016C14 ), which is of the Liaoning association for science and technology innovation base; and serving the local economic soft science project " study on the current situation of 'double - creation' environment in Benxi and the countermeasures of construction and improvement( 20162rkx-01 )"; also serving the local economic project " Research on cultivating college students' entrepreneurial awareness and enhancing their employability under the background of economic transformation in Benxi( 1611211 )"; Education evaluation association society in Liaoning province "research on evaluation of entrepreneurship education curriculum construction in applied technology universities( PJHYYB17144)".

\section{References}

[1] Guo Yuanyuan. Research on the application of "flipped classroom" in efficient classroom teaching [D]. Hebei Normal University, 2015.

[2] Pan Guo, Ouyang Hongwei, Xiang Mingyue, Sun Xiaoqing. Innovation and practice of teaching design of skills courses in colleges and universities based on "flipped classroom" [J]. Forum on Contemporary Education, 2017 ( 05 ): 99 - 106.

[3] Ministry of Education of the People's Republic of China-education information ten years development plan ( 2011 - 2020 ) [Z]. 2012 - 05 - 06. 